\title{
Stakeholders Analysis for Creative Industry Development
}

\section{Liana Mangifera}

Management Program in Economic Faculty and Business, Muhammadiyah University, Surakarta, Indonesia

Corresponding Author: liana.mangifera@ums.ac.id

Recieved: March 2018 | Revised: May 2018 | Accepted: November 2018

\begin{abstract}
This study aims to identify the stakeholders involved in the development of creative industry,as well as describe the various interests of stakeholders in the creative industry and formulate strategies for developing creative industry in Sukoharjo regency. The method used is a mixed approach. Descriptive analysis used to explain the types and interests of stakeholders involved in the creative industry in Sukoharjo District, and to explain the strategy of developing creative industry. Quantitative analysis in this study uses stakeholder analysis that is used to explain the relationship and the role of stakeholders in the development of creative industry. The results show that not all stakeholders are actively involved in the development of creative industry and that every stakeholder has different interests. Therefore to optimize the development of creative industry a forum for communication container is needed and coordination among stakeholders in creative industry development in Sukoharjo regency.
\end{abstract}

Keywords: creative industry, interest, influence, stakeholders

JEL Classification: 025

How to Cite: Mangifera, L. (2018). Stakeholders Analysis For Creative Industry Development. Jurnal Ekonomi Pembangunan: Kajian Masalah Ekonomi dan Pembangunan, 19(2). doi:https://doi. org/10.23917/jep.v19i2.5467

DOI: https://doi.org/10.23917/jep.v19i2.5467

\section{Introduction}

The creative industry is an industry that is derived from the utilization of creativity, skill and talent of the individual to create prosperity and employment through the creation and utilization of power creation and creativity of the individual (Pratt, 2004). Creative industrial development model is a building that will strengthen the economy of Indonesia, with the runway, the pillars and the roof as the building elementsagricultural elements. The current efforts of the Government in order to build the creative industry is expected to further enhance the ability of innovation and the power of adaptation that had been awakened naturally, instead of just the opposite (Comunian et al, 2011). According to the United Nations Conference on Trade and Development the creative industry are the cycle of creation, production, and distribution of goods and services which use intellectual creativity and capital as the main input; part of a series of knowledge-based activities, focusing on art, which can potentially bring in revenue from trade and intellectual property, comprises products 
that can be touched and intellectuals who can not be touched or artistic merits to the charge of creative, economic value, and destination market; the cross-cutting Nature between art, services, and industry; and part of a dynamic sector of world trade in bam Lazzeretti et al. (2012).

The creative industry is one sector that is expected to become a new economic power in the future along with the condition of natural resources dwindling each year (Mangifera, 2016) . The development of creative industries is the right choice to keep the economy under the conditions of the global crisis (Isa \& Mangifera, 2016). Creative industries can provide a very significant contribution to the economy of the region Isa et al. (2018). Its existence is a part which cannot be separated. According to UNCTAD (2008), many of the creative industries contribute significantly on the economy, namely, an increase in export values, absorption of labor, as well as a contributor to gross domestic product (GDP). The results of the study supported the opinion of the decision explains the creative industries to contribute significantly to the growth of the national economy. In the year 2015, the creative economy sector contributed 852 trillion rupiah against the national GDP (7.38\%), absorbing 15.0 million labor (13.90\%), and export value US $\$ 19.4$ billion (12.88\%). National data shows an increase in the contribution of the creative economy significantly to the national economy from the years 20102015 , that amounted to $10.14 \%$ per year.

The policy of creative Industry have mix might see a range of forms of facilitation of creative content enterprises access to and comfort with industry support from venture capital support, other forms of equity investment, enforcement of competition regulation, and structural regulation. Incubation, business skills development, investment incentives, digital rights management, advances against profit (Chuningham,2004.)

According to the Agency for the Creative Economy creative economic policy direction is to develop superior research and human resource competency on the creative economy sector, increase access to capital for the creative economy, facilitating the availability of infrastructure sectors, increasing the creative sector of the creative economy, increasing economic benefits to the holders of intellectual property rights in the creative sector of the economy, build and strengthen the institutional and regulatory in the creative sector of the economy, established the implementation of the reform of the bureaucracy and the Government's good governance. From a wide diversity of creative economic potential in Indonesia, the Government of Indonesia focus on 16 subsector. The Presidential Regulation Number 72/2015 about changes to The Presidential Regulation number 6/2015 about Creative Economy Agency reclassify had subsector creative industry sub-sectors of 15 to 16 sub-sectors, namely the culinary; architecture; product design; interior design; graphic design; film, animation and video; music; fashion; performing arts; games and applications; craft; radio and television; fine art; advertising; photography; as well as publishing.

Creative industries in Sukoharjo Regency potentially developed by businessmen. Economic growth in Sukoharjo Regency widely supported by the industry sector, one of the creative industry (Mangifera, 2016). In 2015 the industry sector was the sector with the highest contribution to the GDP of Sukoharjo Regency i.e. 10.368 trillion, or $38.87 \%$. However, seen from the growth rate for the year 2011-2015 show the numbers decreased. In the year 2015 the growth amounted to $2.98 \%$ decrease compared to the year 2014 of $6.54 \%$. Potential handicraft products in Sukoharjo Regency which are rattan, loom, guitar, goyor gloves, glass carvings, calligraphy, gamelan, bark, herbs and batik. The existence of the creative industry in Sukoharjo Regency is prevalent in some districts. Gamelan is located in Wirun Mojolaban, guitar is located in Grogol, Shuttelcok is located in Gadingan Mojolaban, Rattan craft is located in Trangsang Gatak; grafir in Manang Baki, creative tourist village is located in Kenep 
Sukoharjo. This creative industry contributes to some aspect of life, not only in terms of sheer economic, but also give a positive impact to other aspects such as improvement of the image and identity of the nation, fostering innovation and creativity of the nation, the industry is using renewable resources, as well as positive social impact (Srimulyati et al., 2017).

Competitive creative industries that increasingly stringent demands the perpetrators attempt to more creative in determining its business strategy so that was able to compete (Eikhof, 2015). The development of creative industries in Sukoharjo Regency became very important given the magnitude of the potential of the creative industry and its contribution. Creative industries need to be developed, because the creative industries have a significant economic contribution to the region's economy and create a positive business climate, strengthen the image of regional identity, support the utilization of renewable resources, is central to the creation of innovation and creativity, and have a positive social impact (Comunian, 2014). The stages of creative industry development driven by the thought that the stakeholders (academics, business and government) are together delivering the Foundation and pillars form the pillars of the current leads to conditions expected through its role of each form.

Based on the background, this study aimed at analyzing the stakeholders involved in the development of creative industry, describe the various interests of stakeholders in the creative industry and formulate strategies for developing creative industry in Sukoharjo regency.

\section{Research Method}

This research used mixed method approach, which is a combination of quantitative and qualitative approaches. The population of this study was the actors in creative industry in Sukoharjo. The respondents were selected through snowball sampling method. Based on the method, 9 respondents were selected as key informants of creative industri development.

In-depth interviews were carried out to obtain specific information to answer research problems and research objectives by listing questions as a guide for interviewing respondents and key informants. Interviews were conducted on selected key informants who deliberately selected based on their involvement and comprehension in issues related to the creative industri development.

Stakeholder analysis was employed to analyze the involved stakeholders in the effort of creative industri development. Stakeholder analysis as a study undertaken to identify and map stakeholders based on their role and impact in creative industri development. The most probable results, it is necessary to fully understand the actors' projects and intentions, their methods of action on one another, coupled with the constraints imposed on them the MACTOR method was later developed (Godet, 1991a)

MACTOR (Matrix of Alliance and Conflict: Tactics, Objectives, and Recommendations) is an analytical tool used to analyze influences and interests (objectives) of stakeholders. This method is very broad because it can be used for up to 20 related purposes and yet simple and accessible. To obtain accurate results of analysis, an in-depth interview by using questionnaires is required to obtain more comprehensive answer from stakeholders (Ahmed et al., 2009).

The MACTOR input data are formatted following the prescribedcon ventions of: (i) descriptive qualitative data on the actor's plans, motivations, constraints, and means of action (compiled in the actor's strategy table), (ii) the actors' positioning in relation to strategic objectives (compiled as numerical data into an actors by objectives table as to whether the actor is for $(+)$, neutral (0) or against the 


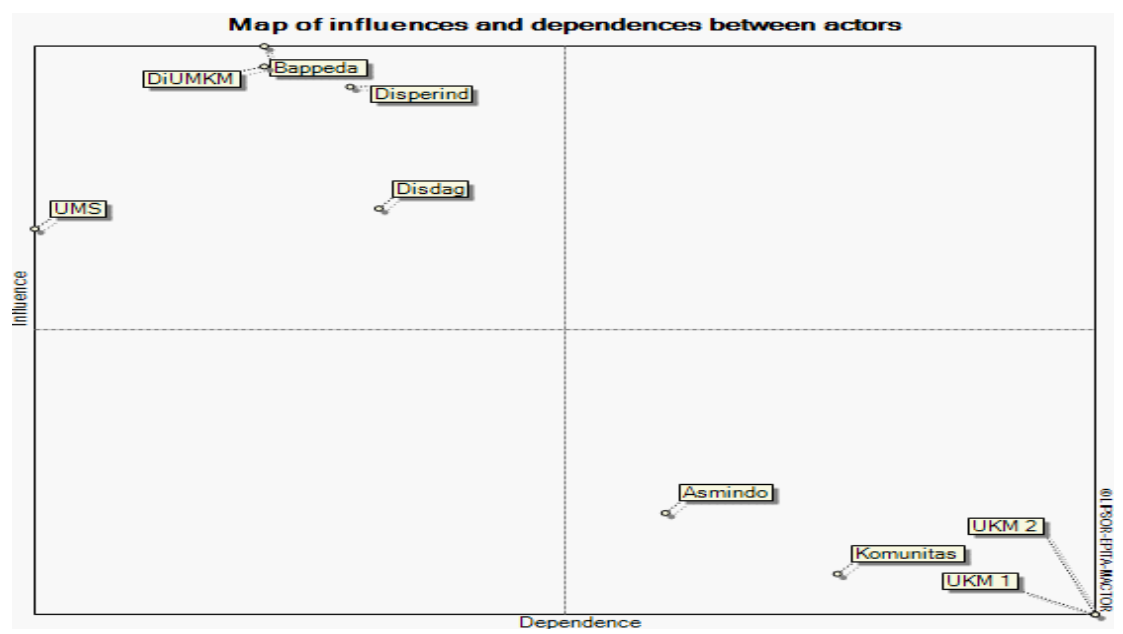

Figure 1. Influence and dependency map between actors

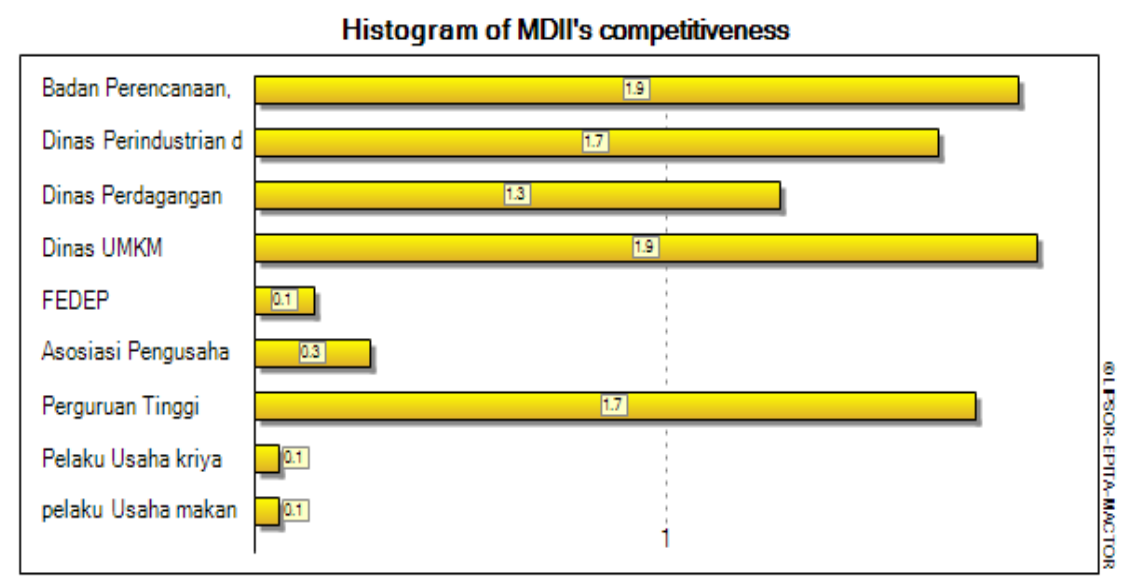

Figure 2. Histogram of Matrix Direct and Indirect Competitiveness

Objective (-) and the relative intensity or salience of the objective's importance to the actor using a scale of 0 (unimportant) to 4 (extremely important)), and (iii) the influence of actors over each other (compiled numerical data as an actor by actor influence table measured on a scale ranging from 0 (no influence) to 4 (very high influence)). The input data are stored as matrices, which the software later multiplies and whose products result in the various analysis outputs. These are in the form of charts and tables that represent the actors' relationships, positions and influences on the future development of the system.
The numerical data are derived through coding the responses to specific questions about an actor's preferences, relationships and how the actor will achieve his or her aims and objectives using the scales

aforementioned. Comprehensive examples and instructions on how to collect, code and enter data and interpret the results can be found in Arcade et al. An example using a more recent version of the software can be found in Godet. (Rees et al., 2017)

MACTOR includes several stages of matrix preparation, namely: (1) determination of key 
variables and relevant actors; (2) preparation of table of actors; (3) preparation of strategic issues and objectives; (4) determination of actors and strategic objectives in the matrix; (5) calculation of convergence and divergence matrices as performed in three stages; (6) calculation of the direct and indirect relationship of power matrix; (7) calculation of the position matrix value; (8) analysis of strategic recommendations of each actor (Godet, 1991b).

\section{Result and Discussion \\ 3.1 Result}

Based on survey and in depth interview, there are 9 stakeholders representing the main actors of creative economic development in Sukoharjo. They are; (1) Department of Planning; Research and Regional Development (Bappeda); (2) Department of SMEs; (3) Department of Commerce; (4) Department of Industry and Labor and, (5) University; (6) Community; (7) Craft Association; (8) Businessman of kriya; (9) Businessman of culinary. The Objectives of creative economy development are : (a) profit, (b) reputation, (c) local culture, (d) the original regional revenue (PAD).

The Mactor Analysis results explain that the influence and interdependence between actors shows how strong the competitiveness of stakeholders in determining the policy to be formulated. The higher the competitiveness, the stronger the influence of stakeholders in accommodating the interests of each stakeholder. The result of Mactor also indicate the level of approval of the actor against the objectives to be formulated. Furthermore, the result of Mactor will show the convergence and divergence between actors

The first result shows the map of influence and interdependence among actors is a representation of the position of each actor with influence and dependence on each other. MACTOR processing produces Figure 1 and figure 2 .

Figures 1 and 2 show that BAPPEDA and Department of SMEs have the highest influence so that their competitiveness is high. These results indicate that BAPPEDA and Department of SMEs have a central role in develop of creative industries in Sukoharjo. The actor with the lowest influence and high dependence is businessman (culinary and craft).

\subsection{Discussion}

The Foundation of the creative industry is people that are the most important elements in the creative industries. The uniqueness of the creative industries - that for almost all industry sectors contained in the creative industries - is the central role of human resources in human capital as compared to other agricultural factors of production factors. To that end, the development of a competitive creative industries should be grounded by the construction of a skilled, trained human resources and to develop knowledge and creativity. It is this knowledge and creativity are becoming the main factors of production within the creative industries.

The building is enclosed under this creative industry by the relationship between theAcademic, Business and Government systems are referred to as triple helix which is the main driving force of actor inception of creativity, ideas, knowledge and technologies that are vital to the growth of the creative industries. Close relationships, mutual support and symbiotes mutualisme between to form 3 the actor in relation to the Foundation and pillar of the agricultural pillar model creative industries will result in creative industries who stand firmly and continuously. Where the third helix that is expected to boost its role in supporting the development of creative industries in Sukoharjo Regency

The next goal is to analyze stakeholder perceptions of the objectives that become indicators. The competitiveness and objectives scale shows that profit, reputation, local culture, and the original regional revenue (PAD) receive positive response from all actors, meaning that all actors agree with these objectives. 
Convergence among actors on creative economy development shows strong values in Department of Planning, Research and Regional Development (Bappeda), Department of SMEs, Department of Commerce, Department of Industry and Labor and, Community, and Craft Association which shows the important position of these actors as they have a high degree of common interest. Stakeholders with the lowest convergence are businessman and academic. The low convergence is related to their high competitiveness, which makes them feel that it is unnecessary to connect with external parties to be empowered.

The convergences matrix on the first order shows the simple convergences between actors which is identification a couple of actors the number of common positions they have on objectives. This matrix would identify the number of possible alliances.

The clustered convergence divided into two major groups. The first group includes businessman (culinary and craft) and academic (university). The second group includes Department of Planning, Research and Regional Development (Bappeda), Department of SMEs,
Department of Commerce, Department of Industry and Labor and, Community, Craft Association. Businessman and academic is an interesting actor because they have influence and independent.

The convergences matrix on second order shows the relationships between actors on objectives. The average convergences will calculate the intensity between actors with the same objectives and will show possibility of intensity alliances with the hierarchy of objectives or preferences between actors. The mactor's result of the second order, there are a very strong convergence network between businesmas craft and Businessman culinary.

The convergences matrix is a weighted matrix that considers the actors, objectives and competitiveness of each actor. The influence and dependence of actors as a weighted. Bappeda have a strong network with department of SMEs. While other actors have moderate and weak networks. The results of mactor indicate that Department of Planning, Research and Regional Development (Bappeda) is actor that can be accepted by all parties and as drivers of the alliance among stakeholders.
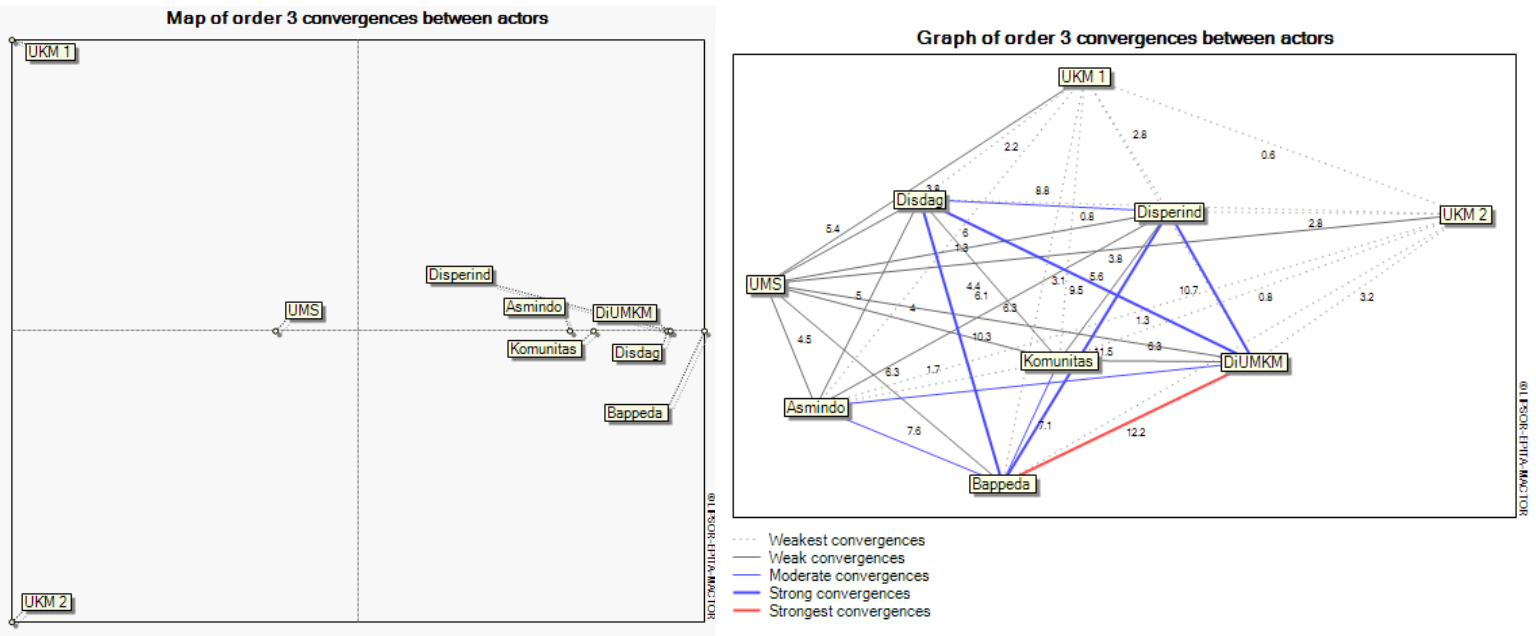

Figure 3. Map and Graph of convergences between actor 


\section{Conclusions}

This result are stakeholders representing the main actors of creative economic development in Sukoharjo are Department of Planning, Research and Regional Development (Bappeda), Department of SMEs, Department of Commerce, Department of Industry and Labor and, University, Community, Craft Association, Businessman of kriya, and Businessman of kuliner. Stakeholders with the highest influence is Bappelbangda, so they can become the central figure in develop of creative industries.

Stakeholders have several objektives di creative industri development. Objectives such as profit, reputation, local culture, and the original regional revenue $(\mathrm{PAD})$ receive positive response from all actors, meaning that all actors agree with these objectives,

Convergence are divided into two groups according to the interests of each stakeholder, there is no divergence according to the interests of each stakeholder. The problem of creative industries development in Sukoharjo is a complex problem that cannot be seen partially because it involves not only economy, but also social, cultural and political issues.

The problem of creative industries development in Sukoharjo is a complex problem that cannot be seen partially because it involves not only economy, but also social, cultural and political issues.

\section{Acknowledgement}

The authors would like to thank LPPI who have contributed in the process of writing this journal. Thank you also to bappeda Sukoharjo regency and SMEs involved for the time and information that has been given so that research activities can run smoothly and well done.

\section{References}

Ahmed, M. T., Abdelkadir, A. F., \& Abdelrehim, A. (2009). El Maghara Scenario A Search for Sustainability and Equity: An Egyptian. Future Journal, 14(November 2009), 55-90.

Comunian, R. (2014). Questioning creative work as driver of economic development: the case of Newcastle-Gateshead This is a working paper
- Please contact the author for permission to quote or disseminate ., (December 2009). https://doi.org/10.1386/cij.2.1.57/1

Comunian, R., Faggian, A., \& Jewell, S. (2011). Winning and losing in the creative industries : an analysis of creative graduates 'career opportunities across creative disciplines, 20 December, 291-308.

Eikhof, D. R. (2015). Creativity and innovation, or : What have the arts ever done for us?, (2015).

Godet, M. (1991a). Actors'Move and Strategis : The MACTOR Method An air transport. Futures Journal, (August), pp 605-622.

Godet, M. (1991b). Actors 'Moves And Strategies : The Mactor Method An air transport, (August).

Isa, M., \& Mangifera, L. (2017.). Chapter 7 : Institutional Reinforcement Model of Creative Economic Development at Surakarta City, (2017), 71-86.

Lazzeretti, L., Capone, F., \& Boix, R. (2012). Reasons for Clustering of Creative Industries in Italy and Spain, 20(8).

Mangifera, L., (2016). Pengembangan Industri Kreatif Produk Batik Tulis Melalui Value Chain Analysis. The $3^{\text {rd }}$ University Research Colloqium ( URECOL), pp 157-166.

Chuningham S.(2004). From Cultural to Creative Industries: Theory, Industry, and Policy Implications.

Pratt, A. C. (2004). The cultural economy A call for spatialized "productionofculture"perspectives. https://doi.org/10.1177/1367877904040609

Rees, G. H., Zealand, N., Macdonell, S., \& Zealand, N. (2017). Data gathering for actor analyses: $A$ research note on the collection and aggregation of individual respondent data for MACTOR, 115-137.

Srimulyati, T., et al (2017). Creative Economy / Creative Industry Development in Indonesia. International Journal of Innovative and Applied Research ,ISSN 2348-0319, Volume 5, issue 5, pp 71-75. 